last of all, individual letters. I do not know of any more convincing proof which could be brought forward to demonstrate that these different groups of visual memories are deposited in distinct cerebral areas. If the centre was simply the general repository of these visual memories without any definite grouping or arrangement of them then there would have been a gradual simultaneous recovery of numbers, words, and letters, which was not the case. On the other hand, if these three distinct groups of visual memories are deposited in definite and distinct areas within this centre, then as the blood-supply is gradually restored, enabling the successive areas to resume their functional activity, it is to be expected that the patient would regain the different groups of visual memories in successive order, as actually took place in the case under consideration. It is to be observed that the order of recovery is not from the simple to the complex but that the power of recognising words was recovered before the power of recognising letters. This order of recovery was also observed in Case 5 already briefly quoted.

The order of events cannot therefore be explained simply by a gradually increasing functional activity of the centre as a whole, nor do I see any other way in which the phenomena observed can be intelligibly explained than on the ground of distinct areas within the centre being occupied with these different groups of visual memories-numbers, words, and letters.

In this series of four papers an attempt has been made to give some reasonable explanation of the phenomena observed in the various forms of "mind-," "word-," and "letterblindness." The views set forth therein have been arrived at by a minute analysis of cases observed and by a critical study of the clinical observations of others. They have the merit of simplicity and of rendering more intelligible the varied and manifold phenomena met with in these conditions.

Glasgow.

\section{A CASE OF TUMOUR OF THE UTERUS COMPLICATED BY TWIN PREGNANCY; CESAREAN SECTION; RECOVERY.}

BY E. R. C. EARLE, M.B. LoND., M.R.C.S. ENG., L.R.C.P. LOND.,

GOVERNMENT MEDICAL OFFICER, LUCEA, JAMAICA.

ON August 20th, 1898, I was called to attend a black woman who had been in labour since the evening of the 18th. The labour pains were strong and frequent, but the labour had not progressed and she was in great pain. After examining the patient $I$ ordered her to be removed at once to the Lucea Hospital with a view to the performance of Cæsarean section. The following is a short account of the case compiled from the notes taken on the hospital case sheet. I may add that I was ably assisted in this operation by Dr. C. M. Phillips and Mr. J. J. Rogers, the Government Medical Officer at Green Island.

The patient was a black woman, about thirty years of age, and was admitted into the hospital at 9 A.M. on August 20th, 1898 . She had been in labour since the evening of the 18th. The abdomen was very much distended and the labour pains were frequent and strong. On vaginal examination a large, firm, elastic tumour was found occupying the pelvic brim and projecting into the upper part of the pelvic cavity. There was a space of about an inch between the anterior surface of the tumour and the symphysis pubis and a similar space on each side between the tumour and the pelvic brim. The tumour was fixed and could not be moved. The os uteri could not be felt at first, but on curving the index finger behind the symphysis and pushing it up as far as possible the os was felt above the pubes slightly to the left of the middle line. The os was partially dilated and flattened antero-posteriorly, simulating a slit-like opening, and was on a level with the upper border of the symphysis. When the patient assumed the upright position the distension of the abdomen was most noticeable and on examination per vaginam in this position the os could not be felt with the finger. Dr. Phillips and Mr. Rogers having examined the patient in consultation with me it was decided to perform Cresarean section without delay. A vaginal douche was administered and the rectum was emptied by an enema. The urine was drawn off by a catheter and the abdominal surface was thoroughly cleansed and asepticised. Chloroform was administered at 11.15 A.M. and the operation commenced at 11.30 A.M. A vertical incision was macle in the middle line 6 in. in length, from 1 in. below the umbilicus to about $2 \frac{1}{2}$ in. above the symphysis, and was continued through the abdominal wall, only two small arteries requiring torsion. The peritoneum was exposed and divided on a director the whole length of the wound. There was no bleeding from the abdominal wound after the two small arteries had been twisted. The uterus was brought forward into the abdominal wound and fixed there by Dr. Phillips. A vertical incision was made in the anterior wall of the uterus commencing near the fundus and extending downwards for about $4 \frac{1}{2} \mathrm{in.}$; the hæmorrhage was rather free. The membranes were ruptured and a male child was extracted by the feet, the head being delivered last. It wast then found that there was another child in the womb situated behind the first, with the head at the fundus and the breech at the lower segment of the womb. This was: quickly extracted, the head coming first and the legs last. There were two distinct placenta which required a considerable amount of manipulation to extract. The hæmorrhage ceased after the placentæ were removed. It was then seen that there was a large solid fibroid tumour of the body of the uterus involving the whole of the posterior surface and right side from the fundus to. the cervix and extending down behind the cervix into the pelvis. The incision happened to be made along the anterior border of the tumour, so that the left lip of the wound in the uterine wall was through normal uterine tissue and the right lip was along the edge of the tumour. There was also a smaller fibroid tumour on the left side of the uterus, of about the size of a small apple. The uterine appendages on either side appeared to be normal. The uterine tumour was 9 in.

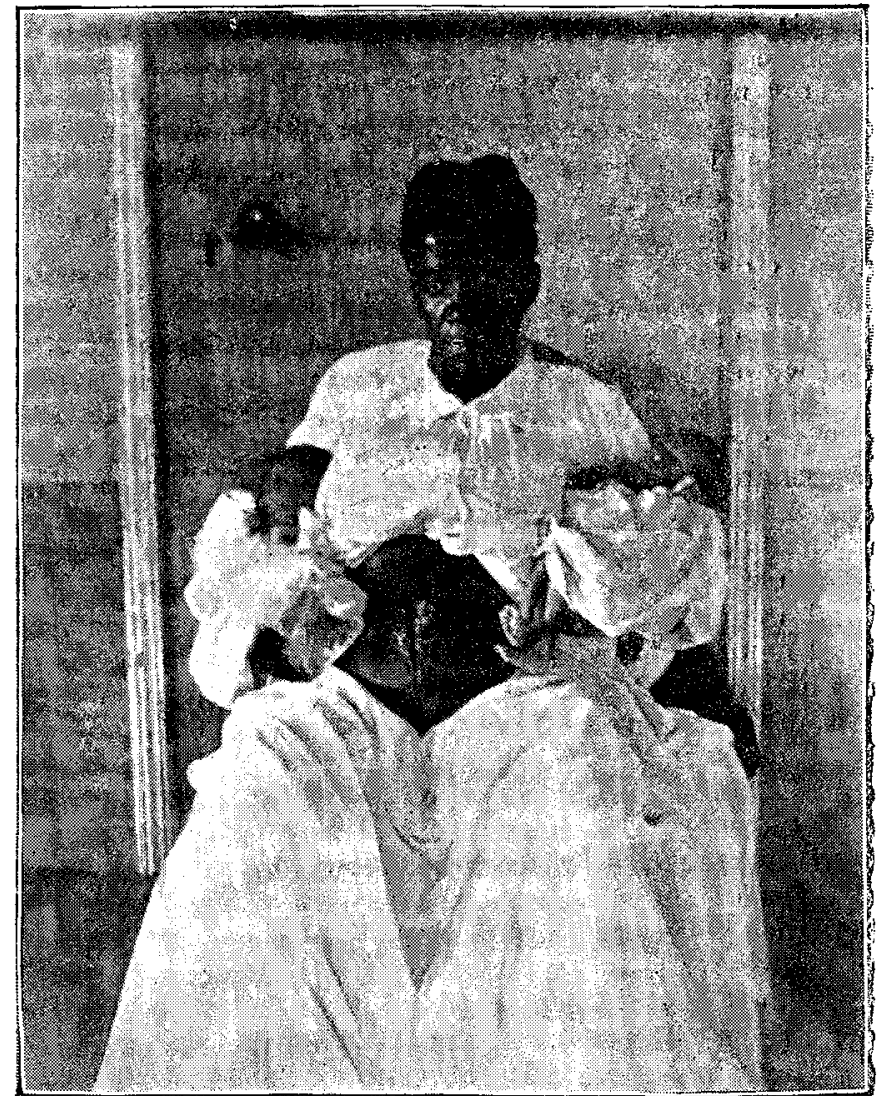

The white marks on each side of the abdominal wound are due to reflected light and not to any discolouration of the skin. The groove is the result of the strapping; it has now gone and the surface of the wound is level with the abdoninal wall.

in length, $7 \mathrm{in}$. from side to side, and about $5 \frac{1}{2}$ in. anteroposteriorly. It was pear-shaped, being broader at the fundus and narrower at the pelvic brim. The uterine: wound was closed by 5 large, deep, silk sutures passed through the uterine wall and 10 small sutures of fine silk through the peritoneum. There was no oozing: through the wound after the application of the sutures. Sponges on holders were passed down into Douglas's pouch and on each side but they returned unsoiled showing that there had been no escape of blood into the 
peritoneal cavity. The parietal peritoneum was then brought together by a continuous fine silk suture and the abdominal wound was closed by 6 large deep sutures, passed through the whole thickness of the abdominal wall, about in. apart, and about 1 in. from the edges of the wound. 10 small superficial stitches were passed through the skin alone and the wound was completely closed. There was no oozing from the wound after it was closed. No drainage tube was passed into the abdominal cavity. The wound was sprinkled with a mixture of boric acid powder and iodoform and covered with a layer of oiled silk. Over this was placed iodoform gauze, sal alembroth gauze, and lint soaked in carbolic acid lotion, and over all a layer of wood-wool dressing, the whole being kept in position by an abdominal bandage. An injection of strychnia ( $\frac{1}{40} \mathrm{gr}$.) was given hypodermically and a morphia suppository ( $\frac{1}{2}$ gr.) was placed in the rectum. The operation was over at 12.30 P.M. and the woman was ceplaced in the bed at 1 P.M. The children were both males-one weighed $5 \mathrm{lb}$. and the other $4 \frac{1}{2} \mathrm{lb}$. They were puny, weak, and thin. When removed from the womb the îrst one did not breathe and the second gave only one or two gasps, but they were both thoroughly revived in ten minutes. The urine was drawn off at 5 P.M. At 4 P.M. the temperature of the patient was $100^{\circ} \mathrm{F}$. and at 8 P.M. it was $101^{\circ}$ when there was no pain, but there was a bloody discharge from the vagina. At 11 P.M. the temperature was $101^{\circ}$ and the pulse was 114. The next day (August 21st) at 6 A.M. the temperature had declined to $99^{\circ}$ and there was neither thrmorrhage in the vagina nor pain in the abdomen. At $10 \mathrm{~A} . \mathrm{M}$. the temperature was $100^{\circ}$ and the pulse was 96 . "The vagina was douched with carbolic lotion ( 1 in 80). The vaginal discharge was normal and without odour. The temperature from 2 P.M. to 2 A.M. on the 22 nd remained at $101^{\circ}$ and the pulse was 108 . The patient slept well on the night of the 21st. She had no hæmorrbage or pain, the lochia were normal, and she took nourishment well. At A.M. the temperature was $99 \cdot 4^{\circ}$ and the pulse was 108 . At 2 P.M. the temperature had risen to $101.6^{\circ}$ and the patient complained of griping pains in the abdomen, her temperature at 6 P.M. being $102 \cdot 2^{\circ}$ and her pulse 126 . The bloody discharge from the vagina was now more copious than before. A douche of carbolic lotion (1 in 80) was administered. At 10 P.M. the temperature had declined to $101^{\circ}$. On the $23 \mathrm{rd}$ the temperature at $6 \mathrm{~A} . \mathrm{M}$. was $99 \cdot 4^{\circ}$ and the patient was doing well. She had slept well at night. Her pulse was 106 . The temperature at 2 P.M. was $101 \cdot 4^{\circ}$. At 5 P.M. another douche was administered. At 10 P.M. her temperature was 101.4. On the 24th the temperature at 6 A.M. was $\mathbf{3 0 0} 4^{\circ}$. The patient had slept fairly well and had had no vain or hæmorrhage. She was, in fact, very comfortable. At 2 P.M. the temperature was $102 \cdot 6^{\circ}$. The discharge from the vagina was copious and in large clots, but the odour was normal. The vagina was douched again. The patient complained of pain in the breasts. At 6 P.M. the temperature was $104 \cdot 4^{\circ}$ and the pulse was 122 . The odour of the discharge was normal. The left breast was rather full and the tongue was slightly furred, the temperature at 9 P.M. being $102^{\circ}$. On the 25 th the temperature at $3 \mathrm{~A} . \mathrm{M}$. rad declined to $99.8^{\circ}$ and at $7 \mathrm{~A} . \mathrm{M}$. to $99.4^{\circ}$. The patient had slept well, but had pain in the back. At $9.30 \mathrm{A.M}$. the wound was dressed for the first time, when there was no soiling of the dressings and the wound had partially united by first intention. The discharge from the vagina was free and normal and the pulse was good. The temperature at 4 P.M. was $103 \cdot 2^{\circ}$ and the pulse was 106 At midnight the temperavure was $103^{\circ}$. On the 26t' at 6 A.M. a soap-and-water enema was administered. The lochia were greenish in colour out normal and there was no pain in the breasts. The temperature was $102^{\circ}$ and the pulse was 106 . At 5 P.M. the temperature was $103.4^{\circ}$ and at 11 P.M. it was $101^{\circ}$. On the 27 th at 6 A.M. one large and four small stitches were removed. A slight amount of thin purulent fluid exuded from one of the large stitches. The temperature was $102^{\circ}$ and the pulse was 114. At 1.30 P.M. the temperature was $103.2^{\circ}$ and at 9 P.M. it was $101 \cdot 6^{\circ}$. On the 28 th at 7 P.M. an enema was given and the bowels were freely opened. The temperature was $101.2^{\circ}$ and at 1.10 P.M. it was $102 \cdot 6^{\circ}$. On the 29th I found that she had passed a restless night and this morning she lost the power of motion on the left side and her speech was indistinct. There was pain in the right side of the chest and the back. The wound was dressed and looked well, but there was a slight discharge from its lower end. There was no tenderness over the womb.
The patient rapidly recovered the power of motion and of speech. The lochia were less but were normal. Both lungs were found to be much congested at the bases at the back. The temperature at 7 A.M. was $101^{\circ}$ and at 4 P.M. 102.4. On August 30th the patient's condition was better. Her speech was clear, the abdominal wound was healing, and the vaginal discharge was normal. The temperature at 9 A.M. was $101 \cdot 4^{\circ}$ and at 10 P.M. it was $102 \cdot 6^{\circ}$. The pulse at 9 A.M. was 98 . On the 31 st the temperature kept at $101^{\circ}$ during the day, and on Sept. Ist, at 9 A.M., it was $99.6^{\circ}$ with a pulse of 92 . At 5 P.M. the temperature became normal and remained so on the 2 nd with a pulse of 86 . On the 3 rd it was $99.4^{\circ}$ all the day and the patient was much improved and stronger. The improvement continuing, on the 4th four stitches were removed. The wound was healing. From this day until the 10th the temperature did not rise above $99 \cdot 4^{\circ}$. On that day at 6 P.M. it was $101.4^{\circ}$ and at 10 P.M. it was $102^{\circ}$, with a pulse of 120 . On the 11th the temperature became normal and the pulse was normal also. The abdominal wound was now quite healed and the uterine tumour was much smaller. On the 15th the patient began to walk about the ward and on the 20 th she was discharged.

This case of Cæsarean section is interesting in many ways. It shows in a remarkable manner the fact that the presence of a large fibroid tumour of the body of the womb of the dimensions above mentioned did not interfere with the progress of a twin pregnancy to the full term, nor did it prevent the normal uterine tissue from contracting and retracting firmly after the removal of its contents as shown by the normal amount of lochia passed during the puerperium. The only abnormal symptom which occurred was the continued high temperature which was undoubtedly due to the severe congestion of the lungs which lasted for some days. A dose of sulphate of quinine ( $30 \mathrm{gr}$.) was given daily during the pyrexia and hot linseed meal poultices were applied to the back and front of the chest and after the pulmonary congestion had subsided the chest was wrapped in cotton wool. During the fever the lochia remained perfectly normal and she never had any symptoms to be referred to the womb itself. The abdominal wound healed without any trouble with the exception that a slight amount of pus collected in two of the larger stitches which was caused by tension. After the tension was relieved by strapping the wound healed readily. The bowels were opened on August 26th by a soap-and-water enema and on Sept. 1st they acted normally. The urine was drawn off by a catheter every five hours until Sept. 2nd when she first passed it of her own accord and continued to do so afterwards. Another interesting feature in this case was the remarkable and rapid diminution in size of the fibroid tumour after the operation. A month after the operation it was only about one-third of its original size. This was probably due to the gradual decrease in the blood-supply. The twins were thin, ill-nourished, and weak. I am inclined to think that this was caused by the tumour which used up for its own support a considerable portion of the blood-supply which would otherwise have been devoted to the nourishment of the placentæ. After the pregnancy had ceased and the blood-supply of the uterus had decreased the tumour also rapidly became smaller. The twins are alive at the time of writing (seven weeks after the operation). One of them is strong and healthy but the other is weak and thin and is evidently very delicate. The mother is quite well and strong and the fibroid tumour is causing her no inconvenience.

Lucea, Jamaica.

\section{A CASE OF OPERATION FOR EXTREME MYOPIA.}

BY ROBERT BRUDENELL CARTER, F.R.C.S. ENG., CONSULTING OPHTHALMIC SURGEON TO ST. GEORGE S HOSPITAL.

ThE possibility of curing a high degree of myopia by the removal of the transparent crystalline lens has of course been present to the minds of ophthalmic surgeons from the time when the refraction of the eye first received careful consideration, but until recently the risks of the operation were rightly held to outweigh the prospects of benefit from its performance. It is only since these risks have been 